\title{
ADAM23, a Gene Related to LGI1, Is Not Linked to Autosomal Dominant Lateral Temporal Epilepsy
}

\section{Laura Rigon, ${ }^{1}$ Andrea Vettori, ${ }^{2}$ Giorgia Busolin, ${ }^{1}$ Gabriella Egeo, ${ }^{3}$ Patrizia Pulitano, ${ }^{3}$ Lia Santulli, ${ }^{4}$ Elena Pasini, ${ }^{5}$ Pasquale Striano, ${ }^{6}$ Angela la Neve, ${ }^{7}$ Valeria Vianello Dri, ${ }^{8}$ Clementina Boniver, ${ }^{8}$ Antonio Gambardella, ${ }^{9}$ Paola Banfi, ${ }^{10}$ Simona Binelli, ${ }^{11}$ Carlo Di Bonaventura, ${ }^{3}$ Salvatore Striano, ${ }^{4}$ Fabrizio de Falco, ${ }^{12}$ Anna T. Giallonardo, ${ }^{3}$ Oriano Mecarelli, ${ }^{3}$ Roberto Michelucci, ${ }^{5}$ and Carlo Nobile ${ }^{1}$}

\author{
${ }^{1}$ CNR-Institute of Neurosciences, Section of Padua, Department of Experimental Biomedical Sciences, University of Padua, \\ viale G. Colombo 3, 35121 Padova, Italy \\ ${ }^{2}$ Department of Biology, University of Padua, Padova, Italy \\ ${ }^{3}$ Department of Neurological Sciences, La Sapienza University, Roma, Italy \\ ${ }^{4}$ Department of Neurological Sciences, Federico II University, Napoli, Italy \\ ${ }^{5}$ Department of Neurosciences, Bellaria Hospital, Bologna, Italy \\ ${ }^{6}$ Muscular and Neurodegenerative Disease Unit, Institute “G. Gaslini”, University of Genova, 16147 Genova, Italy \\ ${ }^{7}$ Clinic of Neurology, University of Bari, Italy \\ ${ }^{8}$ Department of Pediatrics, University of Padua, Padova, Italy \\ ${ }^{9}$ Institute of Neurology, University Magna Graecia, Catanzaro, Italy \\ ${ }^{10}$ Ospedale di Circolo, Varese, Italy \\ ${ }^{11}$ Foundation Neurological Institute "C. Besta", Milano, Italy \\ ${ }^{12}$ Division of Neurology, Loreto Nuovo Hospital, Napoli, Italy
}

Correspondence should be addressed to Carlo Nobile, nobile@bio.unipd.it

Received 16 September 2010; Accepted 1 December 2010

Academic Editor: A. Vezzani

Copyright (C) 2011 Laura Rigon et al. This is an open access article distributed under the Creative Commons Attribution License, which permits unrestricted use, distribution, and reproduction in any medium, provided the original work is properly cited.

\begin{abstract}
Autosomal dominant lateral temporal epilepsy (ADTLE) is an inherited epileptic syndrome characterized by ictal auditory symptoms or aphasia, negative MRI findings, and relatively benign evolution. Mutations responsible for ADLTE have been found in the LGI1 gene. The functions of the Lgil protein apparently are mediated by interactions with members of the ADAM protein family: it binds the postsynaptic receptor ADAM22 to regulate glutamate-AMPA currents at excitatory synapses and also the ADAM23 receptor to promote neurite outgrowth in vitro and dendritic arborization in vivo. Because alteration of each of these neuronal mechanisms may underlie ADLTE, ADAM22 and ADAM23 are candidate genes for this syndrome. In a previous work, we excluded a major role of ADAM22 in the aetiology of ADLTE. Here, we performed linkage analysis between microsatellite markers within or flanking the ADAM23 gene and ADLTE in 13 Italian families. The results exclude ADAM23 as major causative gene for ADLTE.
\end{abstract}

\section{Introduction}

Autosomal dominant lateral temporal epilepsy (ADLTE; OMIM 600512), also named autosomal dominant partial epilepsy with auditory features (ADPEAF), is a familial focal epilepsy syndrome characterized by ictal auditory auras or aphasia [1-3]. Seizure onset usually occur in the first two decades of life, secondarily generalized tonic-clonic seizures manifest in most patients, and interictal EEGs show mild temporal anomalies in a minority of patients [3, 4]. Familial diagnosis of ADLTE is based on concordance for lateral temporal epilepsy in at least two affected family members, intrafamilial recurrence of epilepsy compatible with autosomal dominant inheritance with reduced penetrance, and normal MRI. Outcome is benign with good drug response in most cases. 


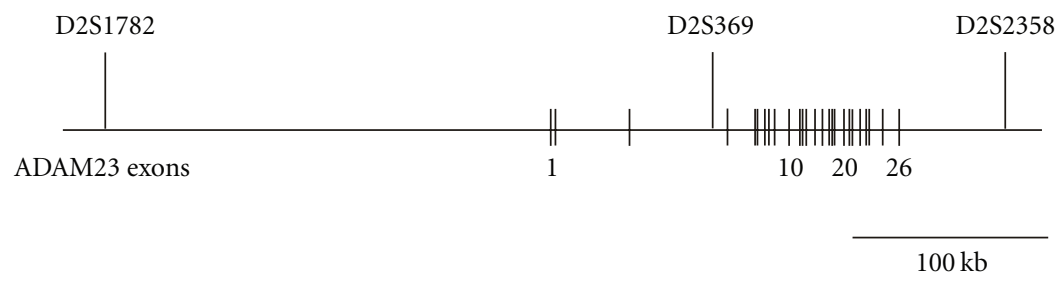

FIGURE 1: Schematic representation of the ADAM23 gene and surrounding genomic region. The positions of individual gene exons (vertical bars) and microsatellites are indicated.

Mutations causing ADLTE are found in the leucinerich, glioma-inactivated 1 (LGI1) gene [5-7]. Overall, LGI1 mutations account for about 50\% of ADLTE families, denoting genetic heterogeneity in ADLTE $[3,8]$.

The LGI1 gene encodes a neuronal protein whose predicted structure consists of a signal peptide, four leucinerich repeats (LRR) in the $\mathrm{N}$-terminal region [9], and seven EPTP (beta-propeller) repeats in the a C-terminal region [10]. Both LRR and beta-propeller domains mediate proteinprotein interactions. The Lgil protein is secreted in vitro [11] and ADLTE-causing mutations hinder protein secretion, suggesting a loss-of-function effect of mutations [7].

The function of the LGI1 gene and the pattern of Lgil protein interactions are not clearly defined. Recent proteomic experiments showed that the Lgil protein forms a complex with the postsynaptic proteins PSD-95 and ADAM22 (a disintegrin and metalloprotease 22) [12]. In addition, it was shown that Lgil acts as a ligand for the receptor ADAM22 and, as a result of this interaction, potentiates postsynaptic AMPA currents at excitatory synapses, whose malfunction may result in epilepsy [12]. On the other hand, Lgi1 was shown to preferentially interact with ADAM23 and through interaction with this receptor, which is not localized to postsynaptic density, stimulates neurite outgrowth in vitro and dendritic arborisation in vivo [13]. Finally, analysis of LGI1 knockout and transgenic mice confirmed interaction of Lgil with both ADAM22 and ADAM23 [14]. These functional studies suggest that ADAM22 and ADAM23 are plausible candidate genes for ADLTE. In previous studies, we and others excluded ADAM22 as a major causative gene for ADLTE $[15,16]$. In this work, we assessed the involvement of ADAM23 in ADLTE by linkage analysis of 13 Italian families.

\section{Methods}

2.1. Family Selection. We included families followed up at nine Italian Epilepsy Centers. Participating members signed written informed consent, approved by the ethics committee of each center. Personal and family history was obtained from each family member along with neurologic examination. Medical records reporting neurophysiologic, neuroimaging, and history data were collected whenever possible. Seizure types were classified according to the Partial Seizure Symptom Definitions [17]. Clinical description was obtained from each patient and/or one close relative who had witnessed at least one episode. ADLTE was diagnosed when two or more family members had focal seizures with auditory features (whistle, buzzing, ringing, voices, music, loss, or attenuation of sounds) and/or receptive aphasia and there was no suspicion of any other focal epilepsy syndrome. EEG recordings were generally performed according to the international 10-20 system with bipolar and referential montages. Sleep EEGs were also performed whenever possible. All patients underwent 1.5-Tesla MRI.

2.2. Genotype Determination and Linkage Analysis. Blood samples were collected from family members. DNA was extracted by standard methods and typed with microsatellite markers, D2S1782, D2S369, and D2S2358, which were chosen for their closeness to the ADAM23 gene (Figure 1). PCR amplification of microsatellites was performed with fluorescently labelled primers in a thermal cycler (MJ research, Waltham MA, USA). PCR products were fractionated on an ABI3100 apparatus (Applied Biosystems). Linkage analysis was performed by using the SuperLink program of the easyLINKAGE package version 5.02; LOD score values were calculated assuming disease-allele frequency of 0.0001 , autosomal dominant inheritance, and penetrance of 0.70 . The phenocopy rate was set at 0.0 . Family members with only FS who were not obligate carriers were classified as non affected.

\section{Results}

3.1. General Data and Clinical Findings. Pedigrees of the thirteen Italian ADLTE families included in the study are shown in Figure 2. Six of them (I-3, I-4, RAN, CTR, PEL, PRO, ZAN) have already been reported $[3,16,18]$; the clinical features of the remaining families will be described elsewhere. Inclusion criteria were (1) two or more family members concordant for lateral temporal epilepsy; (2) absence of potentially causative structural brain abnormalities; (3) inheritance pattern compatible with autosomal dominance with reduced penetrance; (4) absence of mutations in the LGIl gene, as determined by direct sequencing of probands' DNAs. The number of affected members per family varied from 3 to 8 (mean 4.3). In total, there were 56 patients (34 women, 22 men), 44 living. Of these, 32 $(73 \%)$ had lateral temporal seizures with auditory (29) or aphasic (3) phenomena. Age at onset ranged between 6 and 43 years (mean 17.6); perinatal and developmental history as well as neurological examination were unremarkable in all subjects; secondarily generalized tonic-clonic seizures occurred in $25(78 \%)$ patients with auditory or aphasic 


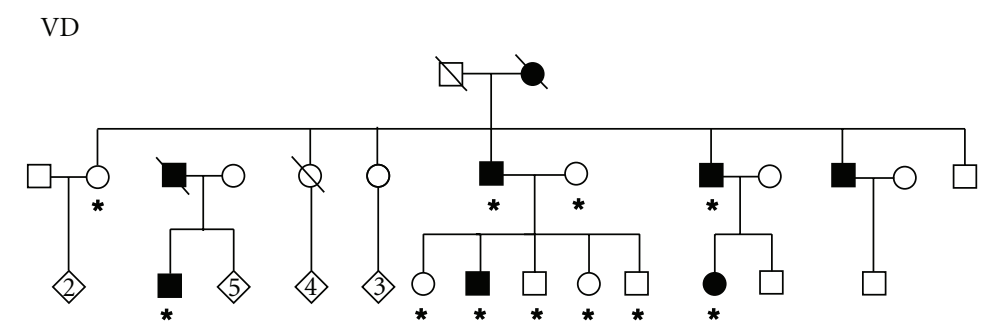

MC
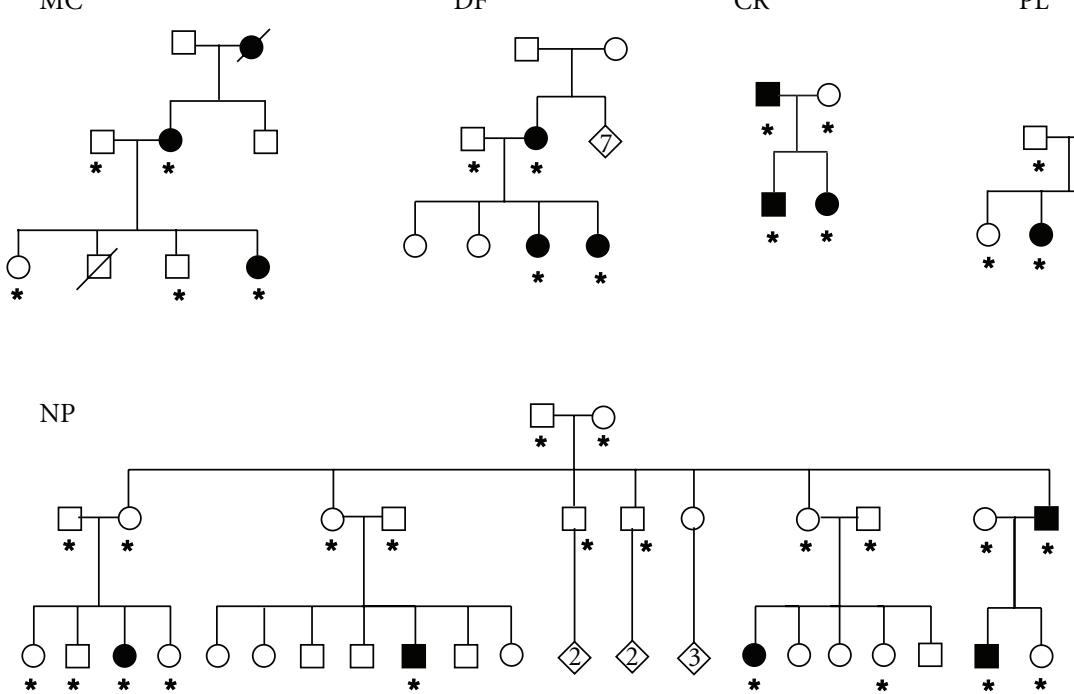

$\mathrm{CN}$

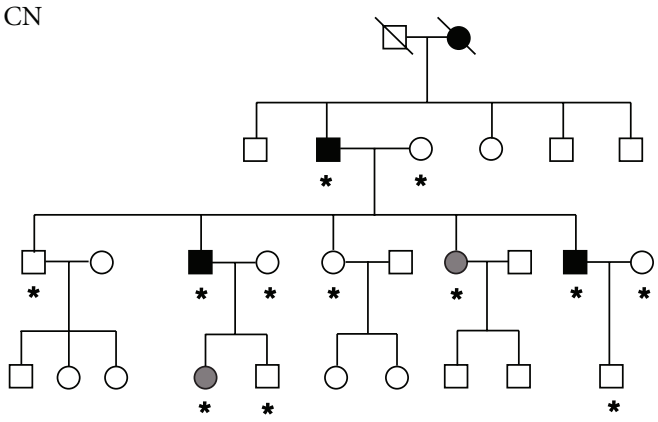

CR
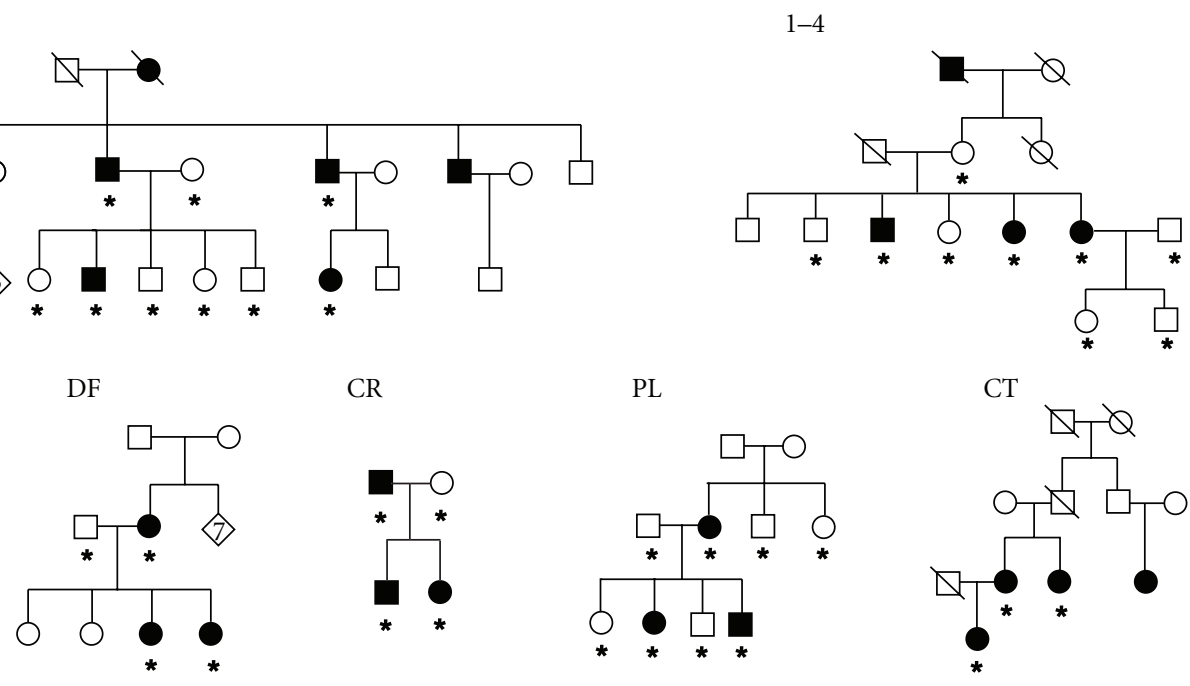

CT

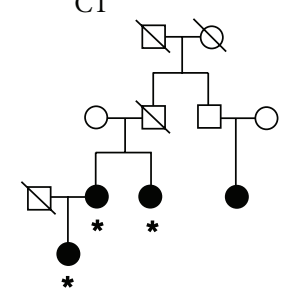

PO

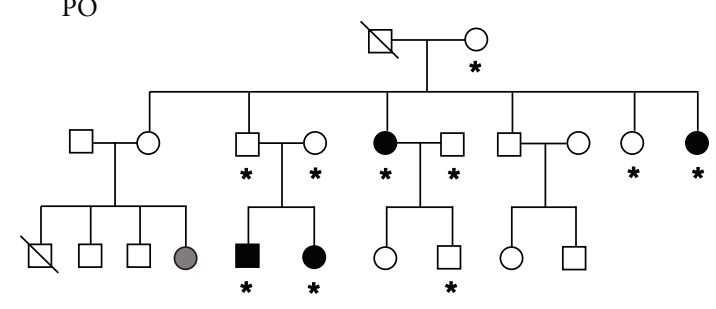

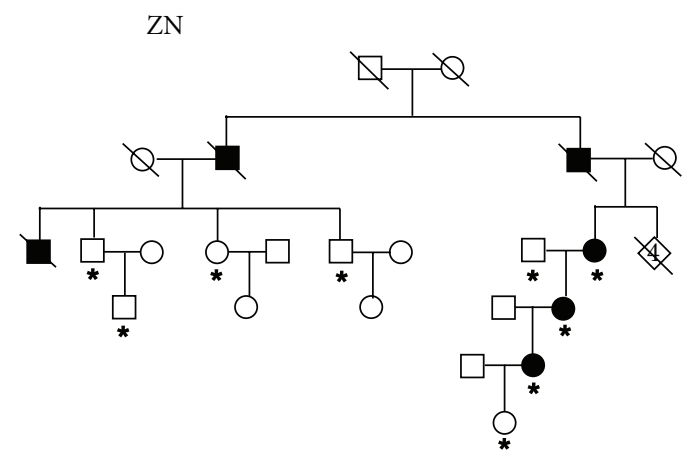

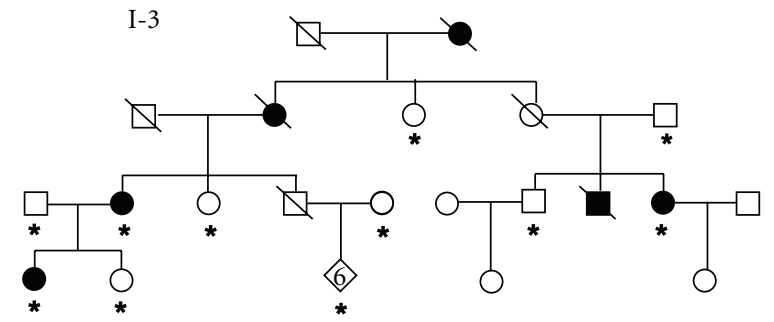

Febrile seizures

FIgURE 2: Pedigrees of ADLTE families. Open squares and circles: unaffected; solid squares and circles: affected; grey square and circles: patients with febrile seizures. Asterisks denote availability of DNAs for linkage analysis. 
TABLE 1

(a) Two-point LOD score obtained at locus D2S1782.

\begin{tabular}{|c|c|c|c|c|c|c|}
\hline \multirow{2}{*}{ Family ID } & \multirow{2}{*}{ Expected maximum LOD score } & \multicolumn{5}{|c|}{ Observed LOD score } \\
\hline & & $\theta=0$ & $\theta=0.1$ & $\theta=0.2$ & $\theta=0.3$ & $\theta=0.4$ \\
\hline $\mathrm{CN}$ & 1.84 & 0.00 & 0.00 & 0.00 & 0.00 & 0.00 \\
\hline $\mathrm{I}-3$ & 1.94 & -2.50 & -0.32 & -0.11 & -0.03 & -0.01 \\
\hline MC & 0.37 & 0.00 & 0.00 & 0.00 & 0.00 & 0.00 \\
\hline NP & 2.55 & -3.01 & -0.53 & -0.24 & -0.10 & -0.02 \\
\hline $\mathrm{I}-4$ & 1.07 & -2.13 & -0.40 & -0.14 & -0.04 & 0.00 \\
\hline DF & 0.30 & -0.19 & -0.01 & 0.03 & 0.03 & 0.01 \\
\hline $\mathrm{CR}$ & 0.30 & -2.41 & -0.25 & -0.09 & -0.04 & -0.02 \\
\hline $\mathrm{CT}$ & 0.20 & -3.13 & -1.03 & -0.61 & -0.35 & -0.15 \\
\hline FE & 0.49 & -2.51 & -0.49 & -0.27 & -0.16 & -0.08 \\
\hline PL & 0.67 & 0.00 & 0.00 & 0.00 & 0.00 & 0.00 \\
\hline $\mathrm{PO}$ & 1.28 & -2.62 & -1.05 & -0.43 & -0.15 & -0.03 \\
\hline VD & 1.84 & -0.46 & -0.28 & -0.15 & -0.07 & -0.02 \\
\hline $\mathrm{ZN}$ & 0.82 & 0.00 & 0.00 & 0.00 & 0.00 & 0.00 \\
\hline Totals & 10.75 & -18.97 & -4.37 & -2.02 & -0.91 & -0.31 \\
\hline
\end{tabular}

(b) Two-point LOD score obtained at locus D2S369.

\begin{tabular}{|c|c|c|c|c|c|c|}
\hline \multirow{2}{*}{ Family ID } & \multirow{2}{*}{ Expected maximum LOD score } & \multicolumn{5}{|c|}{ Observed LOD score } \\
\hline & & $\theta=0$ & $\theta=0.1$ & $\theta=0.2$ & $\theta=0.3$ & $\theta=0.4$ \\
\hline $\mathrm{CN}$ & 1.84 & 0.00 & 0.00 & 0.00 & 0.00 & 0.00 \\
\hline $\mathrm{I}-3$ & 1.94 & -2.50 & -0.32 & -0.11 & -0.03 & 0.00 \\
\hline $\mathrm{MC}$ & 0.37 & -2.83 & -0.44 & -0.19 & -0.08 & -0.02 \\
\hline NP & 2.55 & -3.01 & -0.53 & -0.24 & -0.10 & -0.02 \\
\hline $\mathrm{I}-4$ & 1.07 & -2.30 & -0.09 & 0.03 & 0.04 & 0.01 \\
\hline DF & 0.30 & -3.19 & -0.69 & -0.32 & -0.13 & -0.03 \\
\hline CR & 0.30 & -2.69 & -0.84 & -0.51 & -0.31 & -0.14 \\
\hline CT & 0.20 & -3.25 & -1.76 & -0.95 & -0.48 & -0.18 \\
\hline $\mathrm{FE}$ & 0.49 & -2.36 & -0.32 & -0.12 & -0.04 & -0.01 \\
\hline PL & 0.67 & -0.15 & -0.09 & -0.05 & -0.02 & -0.01 \\
\hline $\mathrm{PO}$ & 1.28 & -3.42 & -1.00 & -0.45 & -0.17 & -0.04 \\
\hline VD & 1.84 & -0.46 & -0.28 & -0.15 & -0.07 & -0.02 \\
\hline $\mathrm{ZN}$ & 0.82 & 0.30 & 0.21 & 0.13 & 0.06 & 0.02 \\
\hline Totals & 10.75 & -25.86 & -6.16 & -2.94 & -1.31 & -0.43 \\
\hline
\end{tabular}

(c) Two-point LOD score obtained at locus D2S2358.

\begin{tabular}{|c|c|c|c|c|c|c|}
\hline \multirow{2}{*}{ Family ID } & \multirow{2}{*}{ Expected maximum LOD score } & \multicolumn{5}{|c|}{ Observed LOD score } \\
\hline & & $\theta=0$ & $\theta=0.1$ & $\theta=0.2$ & $\theta=0.3$ & $\theta=0.4$ \\
\hline $\mathrm{CN}$ & 1.84 & -0.96 & -0.37 & -0.17 & -0.07 & -0.02 \\
\hline $\mathrm{I}-3$ & 1.94 & -2.51 & -0.34 & -0.12 & -0.04 & -0.01 \\
\hline $\mathrm{MC}$ & 0.37 & -2.83 & -0.44 & -0.19 & -0.08 & -0.02 \\
\hline NP & 2.55 & -3.01 & -0.53 & -0.24 & -0.10 & -0.02 \\
\hline $\mathrm{I}-4$ & 1.07 & -2.47 & -0.34 & -0.13 & -0.05 & -0.01 \\
\hline $\mathrm{DF}$ & 0.30 & -0.59 & -0.39 & -0.21 & -0.09 & -0.02 \\
\hline CR & 0.30 & -0.50 & -0.33 & -0.21 & -0.12 & -0.05 \\
\hline $\mathrm{CT}$ & 0.20 & -2.99 & -0.75 & -0.34 & -0.13 & -0.03 \\
\hline $\mathrm{FE}$ & 0.49 & 0.40 & 0.33 & 0.24 & 0.16 & 0.08 \\
\hline PL & 0.67 & 0.00 & 0.00 & 0.00 & 0.00 & 0.00 \\
\hline $\mathrm{PO}$ & 1.28 & -3.42 & -1.00 & -0.45 & -0.17 & -0.04 \\
\hline VD & 1.84 & -0.09 & -0.08 & -0.06 & -0.03 & -0.01 \\
\hline $\mathrm{ZN}$ & 0.82 & 0.00 & 0.00 & 0.00 & 0.00 & 0.00 \\
\hline Totals & 10.75 & -18.96 & -4.23 & -1.88 & -0.70 & -0.14 \\
\hline
\end{tabular}


partial seizures, though at low frequency; and the evolution of the condition was relatively benign since seizures were usually well controlled with standard antiepileptic drugs.

3.2. Genetic Findings. We genotyped our families with three microsatellites (D2S1782, D2S369, and D2S2358) lying within or near the ADAM23 gene (Figure 1). As shown in Table 1, all three polymorphic markers gave negative or inconclusive results in all families. Particularly, LOD scores $<-2$ at Teta 0.0 , which definitely excluded linkage, were obtained with one or more markers in nine families. On the other hand, in four families (CN, PL, VD, and $\mathrm{ZN}$ ) one or more microsatellites gave LOD scores either negative but $>-2$ or slightly positive, as was the case of D2S369 in family ZN, which, however, was lower than the expected LOD score (0.30 versus 0.82$)$. Thus, exclusion of linkage in these four families cannot be considered definitive but only probable. Overall, cumulative LOD scores were definitely negative, ranging from -18.96 to -25.86 (Table 1). These results were confirmed by nonparametric multipoint linkage analysis (cumulative HLOD 0.00; data not shown).

\section{Discussion}

A strategy to identify new ADLTE genes relies on testing candidate genes, such as genes for proteins implicated in the same molecular pathway as Lgil. Recent experimental evidence showed that Lgil preferentially binds to ADAM23, thereby influencing neuronal morphology [13]. Thus, Lgi1 may have a role in the control of neuronal development, which would be impaired in patients carrying LGI1 mutations. This functional model implies that ADAM23 may carry mutations linked to ADLTE at least in part of the families without LGI1 mutations. Our results clearly show that this is not the case and suggest that ADAM23 is not a major gene for ADLTE. This conclusion is strengthened by the methodology we employed, as linkage analysis is more robust than direct sequencing of coding exons, which inevitably overlooks noncoding and large deletion mutations.

An increasing amount of experimental data support interaction between Lgil and several ADAM protein family members [19]. Also, the Lgi4 protein has been shown to bind ADAM proteins in the peripheral nervous system [19]. Thus, there seems to be a molecular affinity between LGI and ADAM protein families, which may provide the molecular substrate of a variety of biological functions. However, it is yet to be proved that this molecular pathway actually underlies ADLTE.

In conclusion, our results exclude that ADAM23 has a major role in the aetiology of ADLTE. Whether this gene has more subtle effects on susceptibility to nonfamilial lateral temporal epilepsy remains to be determined.

\section{Conflicts of Interests}

None of the authors has any conflict of interest to disclose.

\section{Acknowledgments}

The authors wish to thank all the participating families and patients. This work was supported by the Genetics Commission of the Italian League Against Epilepsy (LICE).

\section{References}

[1] R. Ottman, N. Risch, W. A. Hauser et al., "Localization of a gene for partial epilepsy to chromosome 10q," Nature Genetics, vol. 10, no. 1, pp. 56-60, 1995.

[2] E. Brodtkorb, W. Gu, K. O. Nakken, C. Fischer, and O. K. Steinlein, "Familial temporal lobe epilepsy with aphasic seizures and linkage to chromosome 10q22-q24," Epilepsia, vol. 43, no. 3, pp. 228-235, 2002.

[3] R. Michelucci, J. J. Poza, V. Sofia et al., "Autosomal dominant lateral temporal epilepsy: clinical spectrum, new epitempin mutations, and genetic heterogeneity in seven European families," Epilepsia, vol. 44, no. 10, pp. 1289-1297, 2003.

[4] M. R. Winawer, F. M. Boneschi, C. Barker-Cummings et al., "Four new families with autosomal dominant partial epilepsy with auditory features: clinical description and linkage to chromosome 10q24," Epilepsia, vol. 43, no. 1, pp. 60-67, 2002.

[5] S. Kalachikov, O. Evgrafov, B. Ross et al., "Mutations in LGI1 cause autosomal-dominant partial epilepsy with auditory features," Nature Genetics, vol. 30, no. 3, pp. 335-341, 2002.

[6] J. M. Morante-Redolat, A. Gorostidi-Pagola, S. Piquer-Sirerol et al., "Mutations in the LGI1/epitempin gene on 10q24 cause autosomal dominant lateral temporal epilepsy," Human Molecular Genetics, vol. 11, no. 9, pp. 1119-1128, 2002.

[7] C. Nobile, R. Michelucci, S. Andreazza, E. Pasini, S. C. E. Tosatto, and P. Striano, "LGI1 mutations in autosomal dominant and sporadic lateral temporal epilepsy," Human Mutation, vol. 30, no. 4, pp. 530-536, 2009.

[8] R. Ottman, M. R. Winawer, S. Kalachikov et al., "LGI1 mutations in autosomal dominant partial epilepsy with auditory features," Neurology, vol. 62, no. 7, pp. 1120-1126, 2004.

[9] S. G. Buchanan and N. J. Gay, "Structural and functional diversity in the leucine-rich repeat family of proteins," Progress in Biophysics and Molecular Biology, vol. 65, no. 1-2, pp. 1-44, 1996.

[10] E. Staub, J. Pérez-Tur, R. Siebert et al., "The novel EPTP repeat defines a superfamily of proteins implicated in epileptic disorders," Trends in Biochemical Sciences, vol. 27, no. 9, pp. 441-444, 2002.

[11] K. R. Senechal, C. Thaller, and J. L. Noebels, "ADPEAF mutations reduce levels of secreted LGI1, a putative tumor suppressor protein linked to epilepsy," Human Molecular Genetics, vol. 14, no. 12, pp. 1613-1620, 2005.

[12] Y. Fukata, H. Adesnik, T. Iwanaga, D. S. Bredt, R. A. Nicoll, and M. Fukata, "Epilepsy-related ligand/receptor complex LGI1 and ADAM22 regulate synaptic transmission," Science, vol. 313, no. 5794, pp. 1792-1795, 2006.

[13] K. Owuor, N. Y. Harel, D. J. Englot, F. Hisama, H. Blumenfeld, and S. M. Strittmatter, "LGI1-associated epilepsy through altered ADAM23-dependent neuronal morphology," Molecular and Cellular Neuroscience, vol. 42, no. 4, pp. 448-457, 2009.

[14] Y. Fukata, K. L. Lovero, T. Iwanaga et al., "Disruption of LGI1linked synaptic complex causes abnormal synaptic transmission and epilepsy," Proceedings of the National Academy of Sciences of the United States of America, vol. 107, no. 8, pp. 3799-3804, 2010. 
[15] E. Chabrol, I. Gourfinkel-An, I. E. Scheffer et al., "Absence of mutations in the LGI1 receptor ADAM22 gene in autosomal dominant lateral temporal epilepsy," Epilepsy Research, vol. 76, no. 1, pp. 41-48, 2007.

[16] E. Diani, C. Di Bonaventura, O. Mecarelli et al., "Autosomal dominant lateral temporal epilepsy: absence of mutations in ADAM22 and Kv1 channel genes encoding LGI1-associated proteins," Epilepsy Research, vol. 80, no. 1, pp. 1-8, 2008.

[17] H. Choi, M. R. Winawer, S. Kalachikov, T. A. Pedley, W. A. Hauser, and R. Ottman, "Classification of partial seizure symptoms in genetic studies of the epilepsies," Neurology, vol. 66, no. 11, pp. 1648-1653, 2006.

[18] R. Michelucci, D. Passarelli, S. Pitzalis, G. Dal Corso, C. A. Tassinari, and C. Nobile, "Autosomal dominant partial epilepsy with auditory features: description of a new family," Epilepsia, vol. 41, no. 8, pp. 967-970, 2000.

[19] K. Sagane, Y. Ishihama, and H. Sugimoto, "LGI1 and LGI4 bind to ADAM22, ADAM23 and ADAM11," International Journal of Biological Sciences, vol. 4, no. 6, pp. 387-396, 2008. 


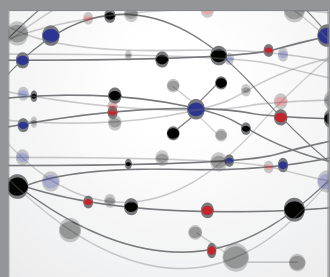

The Scientific World Journal
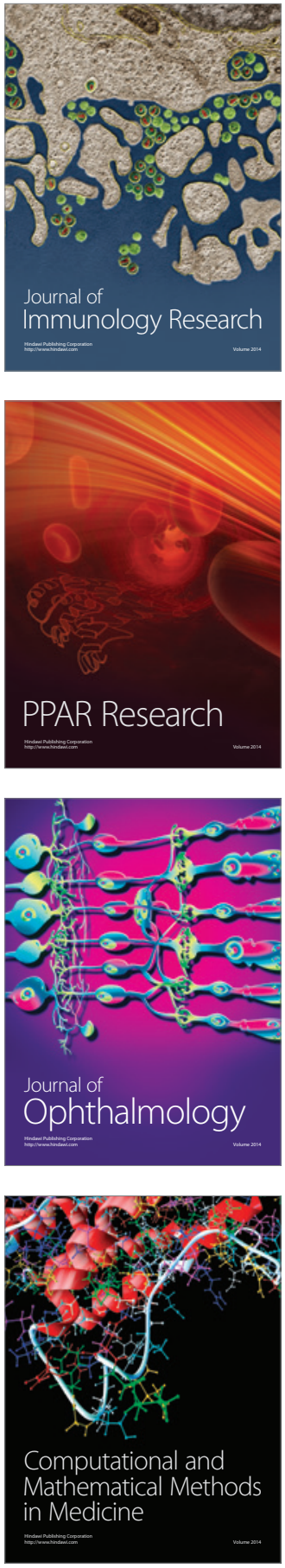

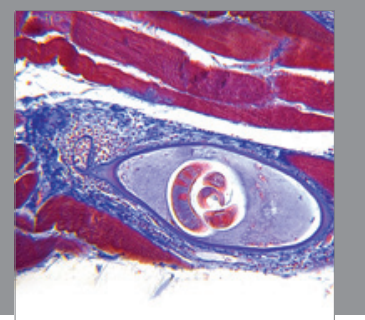

Gastroenterology

Research and Practice
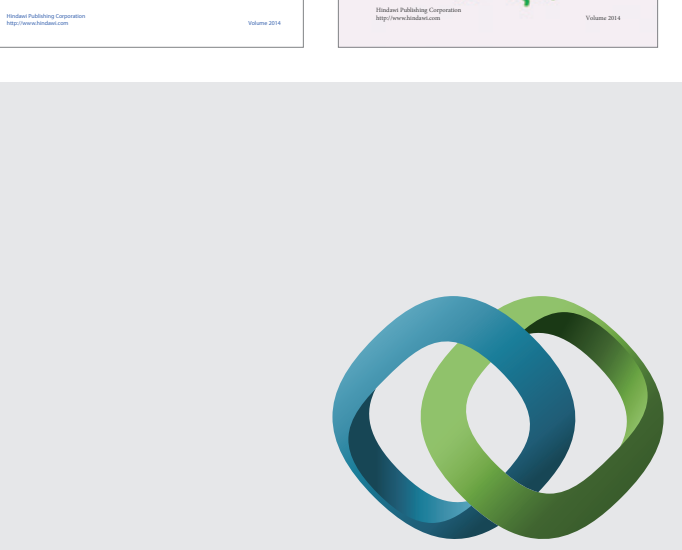

\section{Hindawi}

Submit your manuscripts at

http://www.hindawi.com
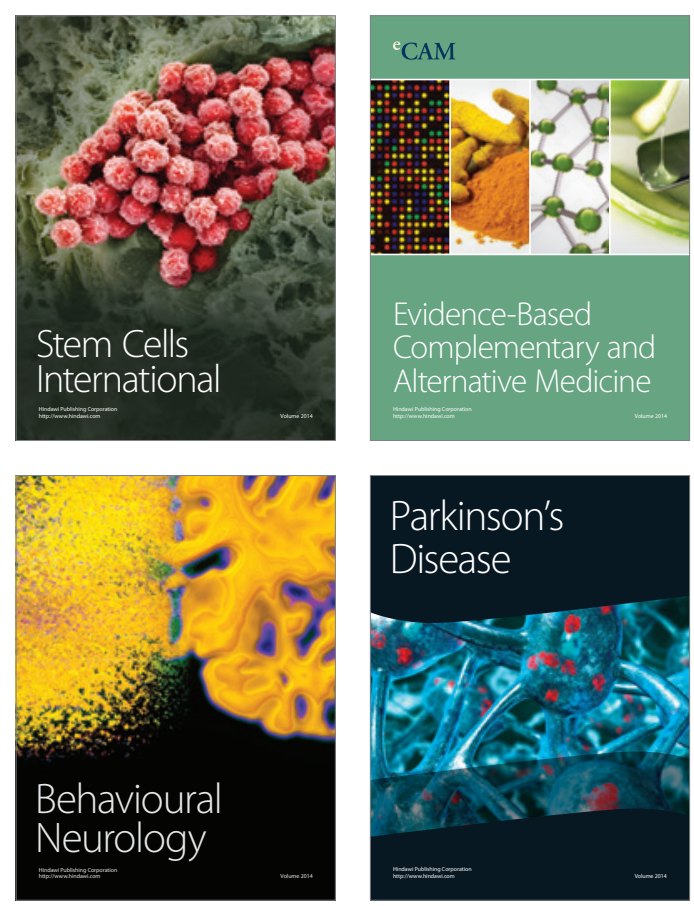

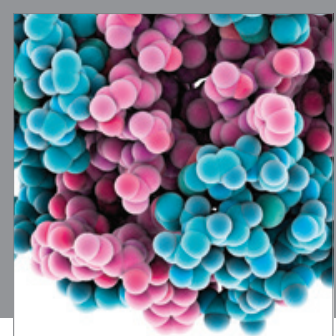

Journal of
Diabetes Research

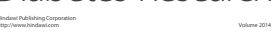

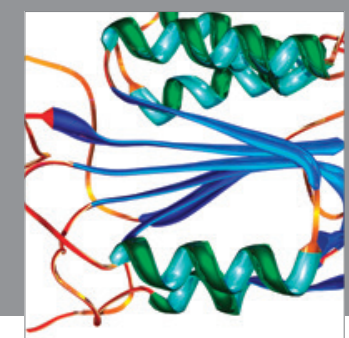

Disease Markers
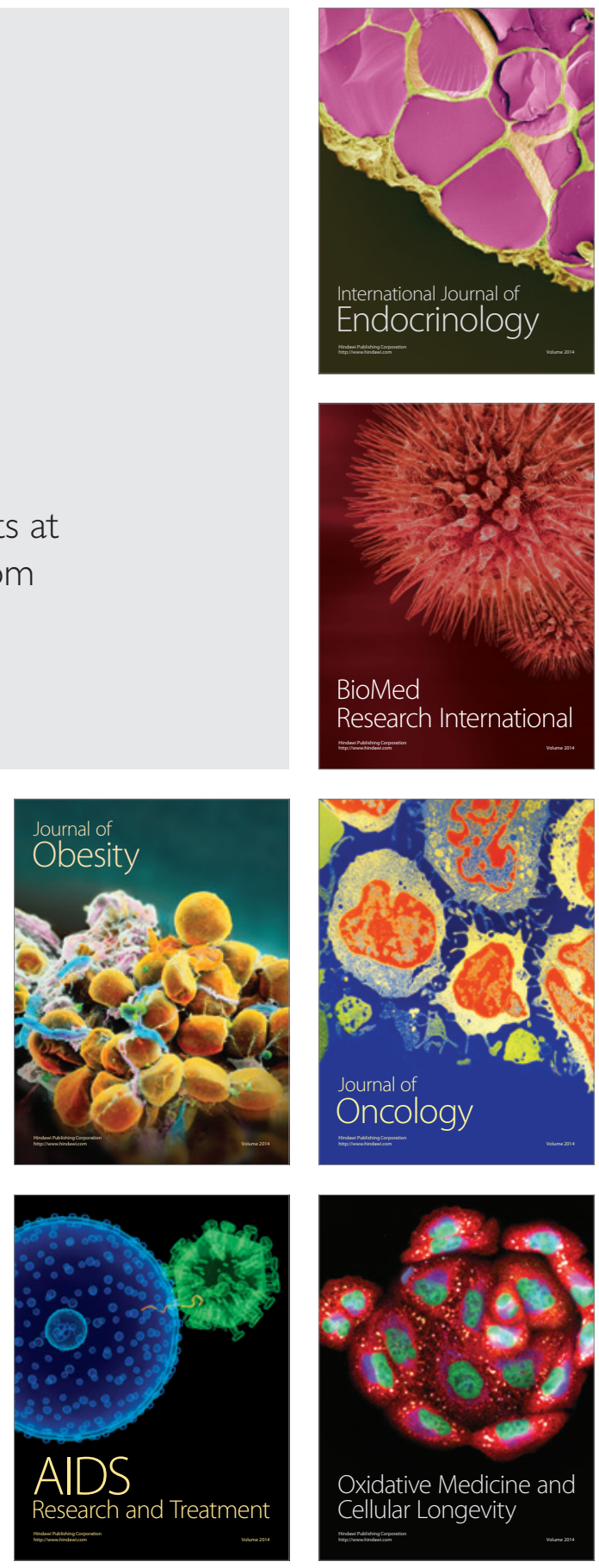